\title{
EXPERIMENTAL ANALYSIS OF EROSIVE COHESIVE COASTLINE MORPHOLOGY
}

\author{
Bastien Caplain ${ }^{1}$, Dominique Astruc ${ }^{1}$, Vincent Regard ${ }^{2}$, Frédéric Y. Moulin ${ }^{1}$
}

\begin{abstract}
Laboratory experiments have been performed in a wave flume to investigate the coastal cliff recession under regular waves forcing. The different processes of the cliff erosion cycle are described and we focus on bottom evolution, which seem mostly depend on the surf similarity parameter $\xi$. We observed steep planar $(\xi>0.7)$, gentle planar $(0.5$ $<\xi<0.7)$ and bared $(\xi<0.5)$ profiles. We noticed different sandbar dynamics including either steady or unsteady self-sustained oscillating states. Then we estimate the role of the self-organized material on the cliff recession rate. We show that the cliff erosion increases with the wave energy flux and is stronger for a gentle planar profile than for a bared profile of bottom morphology. However, the cliff recession rate as a function of the cliff height is not monotonic due to a different dynamics of bottom morphologies.
\end{abstract}

Keywords: cliff erosion; bottom morphology; experimental modeling; beach ridge

\section{INTRODUCTION}

The coastlines of the Earth are composed of about $80 \%$ of rocky coasts; these coasts are composed of either consolidated or unconsolidated rocks such as clay (Collins and Sitar, 2008). Although it is crucial to be able to forecast cliff recession rate at a given location, the different underlying physical mechanisms are not well understood. The main factor controlling the cliff erosion is wave attack, but to mention a few, tidal cycles (Kanyaya and Trenhaile, 2005), lithology, and living organisms (Nesteroff and Mélières, 1967) play also a role. In this work, we focus on erosion controlled by wave attack.

Wave-driven cliff erosion occurs through several different processes. Firstly the waves impact the bottom of the cliff creating a notch growing until the weight of the overlying cliff becomes greater than material strength, causing cliff collapse. This collapse leads to a retreat of the cliff front and therefore a supply of sediment to the beach. Wave-driven sediment transport modifies the bottom morphology; in turn wave dynamics changes due to shoaling and breaking processes. Here, we focus on the bottom change as a function of wave parameters and on sediment supply.

Numerous studies about the bottom morphology were carried out both in situ and in laboratory. In particular, equilibrium beach profiles are defined as profiles which do not evolve for a constant wave climate (Dean, 1991; Wang and Kraus, 2005; Grasso et al., 2009). The concept of equilibrium beach profile is often used to characterize beach morphologies; natural equilibrium profiles were estimated by spatial and temporal averages (Larson and Kraus, 1994). Different types of in situ cross-shore beach profiles were classified depending on wave climate and sand granulometry (Wright and Short, 1984).

The present work consists in an experimental simulation of coastal cliff erosion under wave attack performed in a wave flume. The aim is to reproduce and analyse the cliff erosion dynamics within reasonable time and space scales because such in situ analysis is made difficult by the large time scales involved in natural systems. Damgaard and Dong (2004) already performed such an experiment using a wave basin with a constant slope. The wet sand cliff was located on a flat platform. Incident waves were generated with a wave maker allowing variable wave incidence. They concluded that the cliff recession rate increases with wave height and period, decreases with cliff height. In addition, this rate seems to be constant for oblique waves. In the present work, the experiments were carried out in a $1 \mathrm{D}$ wave flume where only normal incident waves are allowed.

We will introduce the various parameters we chose to vary and we will focus on 2 aspects of the results. First, the self-organization of the bottom morphology is discussed; we observed different types of morphology which tend to a stationary state except in a couple of experiments. Second, we will study the influence of the wave properties and sediment supply on cliff recession rate. A comparison with Damgaard and Dong (2004)'s results is made.

\footnotetext{
${ }^{1}$ Institut de Mécanique des Fluides de Toulouse (IMFT), Université de Toulouse, INPT, UPS ; CNRS, Allée du Professeur Camille Soula, 31400 Toulouse, France.

${ }^{2}$ Laboratoire des Mécanismes et Transferts en Géologie (LMTG), Université de Toulouse, UPS (OMP) ; CNRS ; IRD, 14 Avenue Edouard Belin, 31400 Toulouse, France.
} 


\section{EXPERIMENTAL SETUP / METHOD}

The experiments were performed in a wave flume about $5 \mathrm{~m}$-long, $14 \mathrm{~cm}$-wide and $25 \mathrm{~cm}$-high (Fig. 1) during about 20 hours. The flume is equipped with a flap wave maker producing monochromatic waves with a height up to $5 \mathrm{~cm}$ and periods between $0.5 \mathrm{~s}$ and $2 \mathrm{~s}$. The offshore water depth is $d=15 \mathrm{~cm}$. A nearshore slope of $\tan (\beta)=1 / 10$ is used to model the shore and a cliff is built on the shore with wet sand (Fig. 1). The cliff front is cut to obtain the cliff depth of $40 \mathrm{~cm}$. The initial conditions, in terms of cliff length and water content in material, are identical for every experiment. The cliff height $\mathrm{h}$ is measured from the free surface at rest to the cliff top. The sand used is calcite with a median grain diameter of $\mathrm{d}_{50}=0.41 \mathrm{~mm}$ and a density of $\rho_{\mathrm{s}}=2.76 \mathrm{~g} / \mathrm{cm}^{3}$ (corresponding to a fall velocity in water of $\mathrm{w}_{\mathrm{s}}=6.5 \mathrm{~cm} / \mathrm{s}$ ).

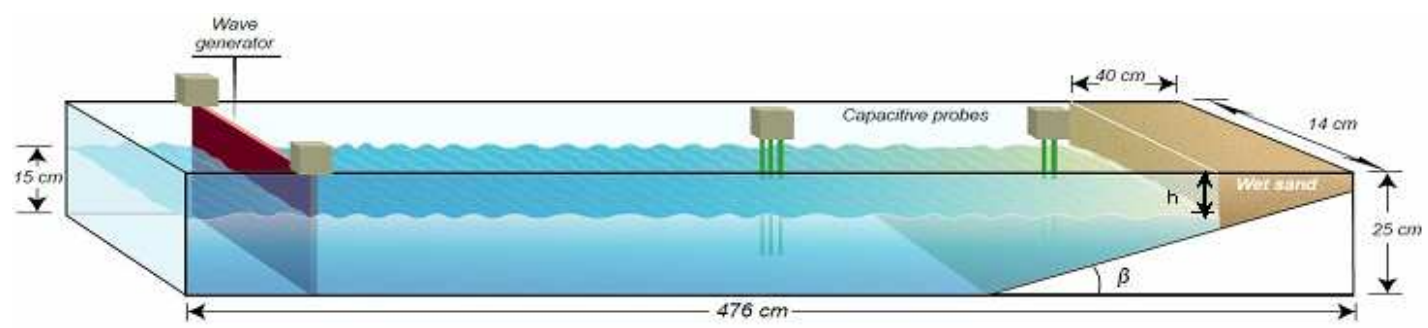

Figure 1. Wave flume model.

Wave parameters are measured by capacitive probes (acquisition at $100 \mathrm{~Hz}$ ). 3 are located offshore and 2 close to the cliff (Fig. 1). The offshore incident wave height $(\mathrm{H})$ is estimated with a least square method and incident and reflected wave height are distinguished (Mansard and Funke, 1980). A summary of test run parameters is given in Table 1.

Two PCO 2000 cameras have been positioned, on the side of the flume (with a field of view $1 \mathrm{~m} \times$ $25 \mathrm{~cm}$ ) to detect the water free surface and the bottom and cliff positions, and above the flume (with a field of view $40 \mathrm{~cm} \times 15 \mathrm{~cm}$ ) to detect the cliff position. During about 4 hours, the video sampling rate is close to the wave frequency and then is decreased to $\sim 1 / 10$ of this frequency until the end of the experiment.

\begin{tabular}{|c|c|c|c|c|c|c|}
\hline \multicolumn{7}{|c|}{ Table 1. Tests conditions. } \\
\hline Test & $\begin{array}{c}\mathrm{H} \\
{[\mathrm{cm}]}\end{array}$ & $\begin{array}{c}\mathrm{T} \\
{[\mathrm{s}]}\end{array}$ & $\begin{array}{c}\mathbf{h} \\
{[\mathrm{cm}]}\end{array}$ & $\boldsymbol{\xi}$ & $\begin{array}{c}\mathbf{F} \\
{[\mathrm{W} / \mathrm{m}]}\end{array}$ & $\begin{array}{c}\text { Duration } \\
{[\mathrm{h}]}\end{array}$ \\
\hline $1-\mathrm{a}$ & 4.1 & 0.66 & 8 & 0.39 & 1.23 & 20.5 \\
$1-\mathrm{b}$ & 3.8 & 0.66 & 8 & 0.40 & 1.09 & 20 \\
$1-\mathrm{c}$ & 4.0 & 0.66 & 8 & 0.39 & 1.17 & 20 \\
$1-\mathrm{d}$ & 3.9 & 0.66 & 8 & 0.40 & 1.14 & 20 \\
2 & 3.5 & 0.59 & 8 & 0.38 & 0.77 & 20 \\
3 & 4.8 & 0.72 & 8 & 0.38 & 1.89 & 20 \\
4 & 4.1 & 0.84 & 8 & 0.46 & 1.63 & 19 \\
5 & 3.5 & 0.93 & 8 & 0.55 & 1.23 & 6 \\
6 & 3.2 & 0.92 & 8 & 0.56 & 1.04 & 3 \\
7 & 3.0 & 0.87 & 8 & 0.56 & 0.88 & 21.5 \\
8 & 2.4 & 1.32 & 8 & 0.78 & 0.74 & 4.5 \\
9 & 4.1 & 0.66 & 10 & 0.39 & 1.27 & 21 \\
10 & 3.9 & 0.66 & 5 & 0.40 & 1.12 & 21 \\
\hline
\end{tabular}

Cliff erosion rate and sediment transport on the bottom are studied in function of incident wave energy, wave shape and cliff height. The monochromatic wave climate is characterized by two parameters, the surf similarity parameter $\xi$ and the incident wave energy flux $F$ which are written

$$
\xi=\frac{\tan (\beta)}{\sqrt{\mathrm{H} / \mathrm{L}}}
$$




$$
F=E \cdot c_{G}
$$

where $\tan (\beta)$ is the bottom slope, $H$ the wave height, $L$ the wave length, $E$ the wave energy density and $\mathrm{C}_{\mathrm{G}}$ the group velocity.

The conditions of experiments carried out are shown in Table 1.

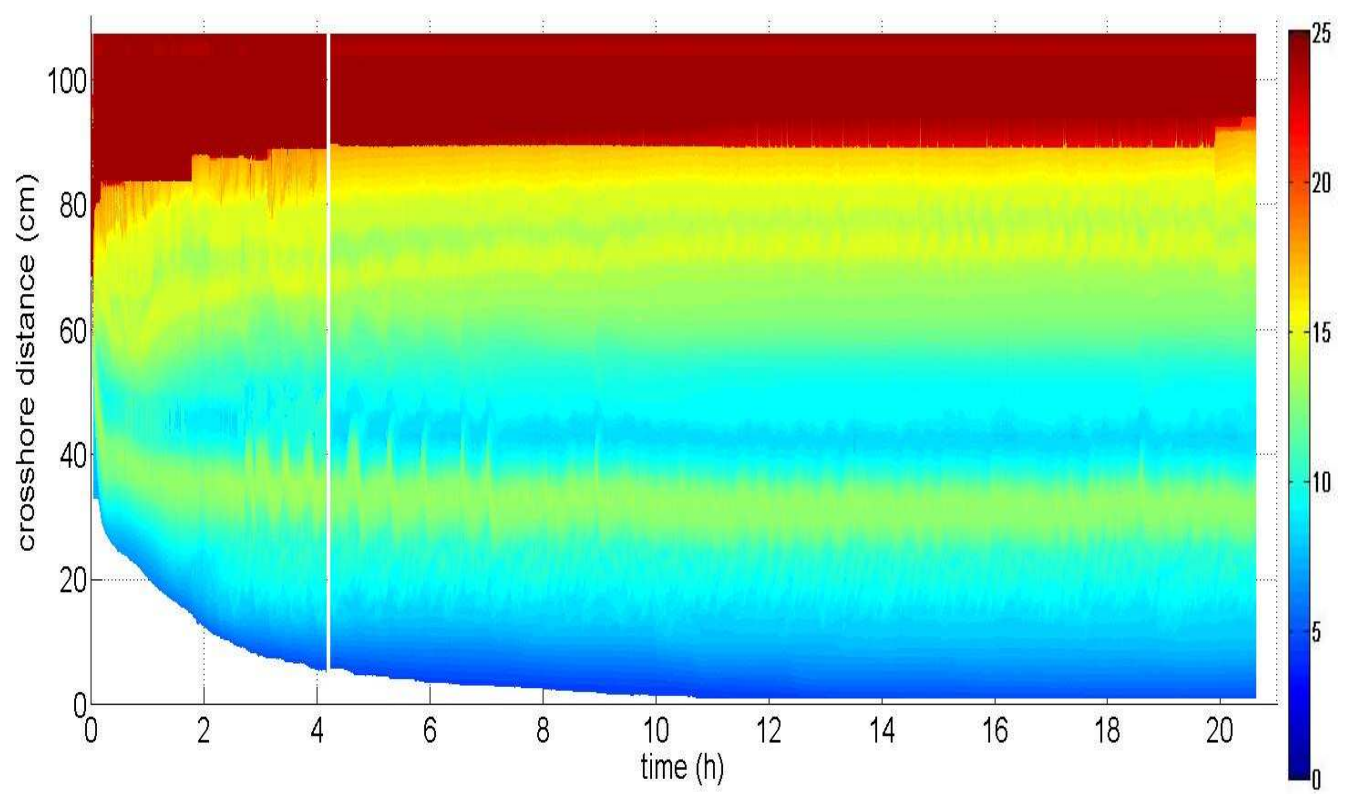

Figure 2. Spatial and temporal evolution of bottom morphology for test 1-a; color scale represents the elevation above flume bottom (in $\mathrm{cm}$ ). Water mean level is $15 \mathrm{~cm}$.

\section{RESULTS AND DISCUSSION}

\section{Reference experiment (test 1 )}

After a cliff drainage of about 2 hours, the flume is filled up to $\mathrm{d}=15 \mathrm{~cm}$. The bottom of the cliff is submerged and an initial notch is formed. Then, the wave maker is activated. At the beginning of the experiment, cliff retreat is very fast and collapsed sediment quickly creates a sandy platform on the slope. The bottom morphology rapidly evolves to a bared profile and plunging breaking waves are observed. Afterwards, the recession rate decreases such that an equilibrium profile is reached (Fig. 2). The experimental setup allows for observing both the emerged and immerged beach.

\section{Bottom morphology}

The influence of the wave climate on the bottom morphology (Fig. 3) is studied in a series of experiments with a cliff height of $8 \mathrm{~cm}$. We observed 3 different types of bottom morphology:

1. For surf similarity parameter values greater than 0.7 , the bottom profile is planar and steep; it corresponds to a reflective platform (Fig. 3-b). Waves break only when interacting with the backwash at the outward edge of the platform.

2. For surf similarity parameter values between 0.5 and 0.7 , the bottom profile is almost planar but with a gentle slope (Fig. 3-c). Breaking waves are spilling above the outward edge of the platform.

3. For surf similarity parameter values less than 0.5 , we observed bared profiles with two sandbars that we will name outer and inner. Breaking waves are plunging above the outer sandbar (Fig. 3-d). 


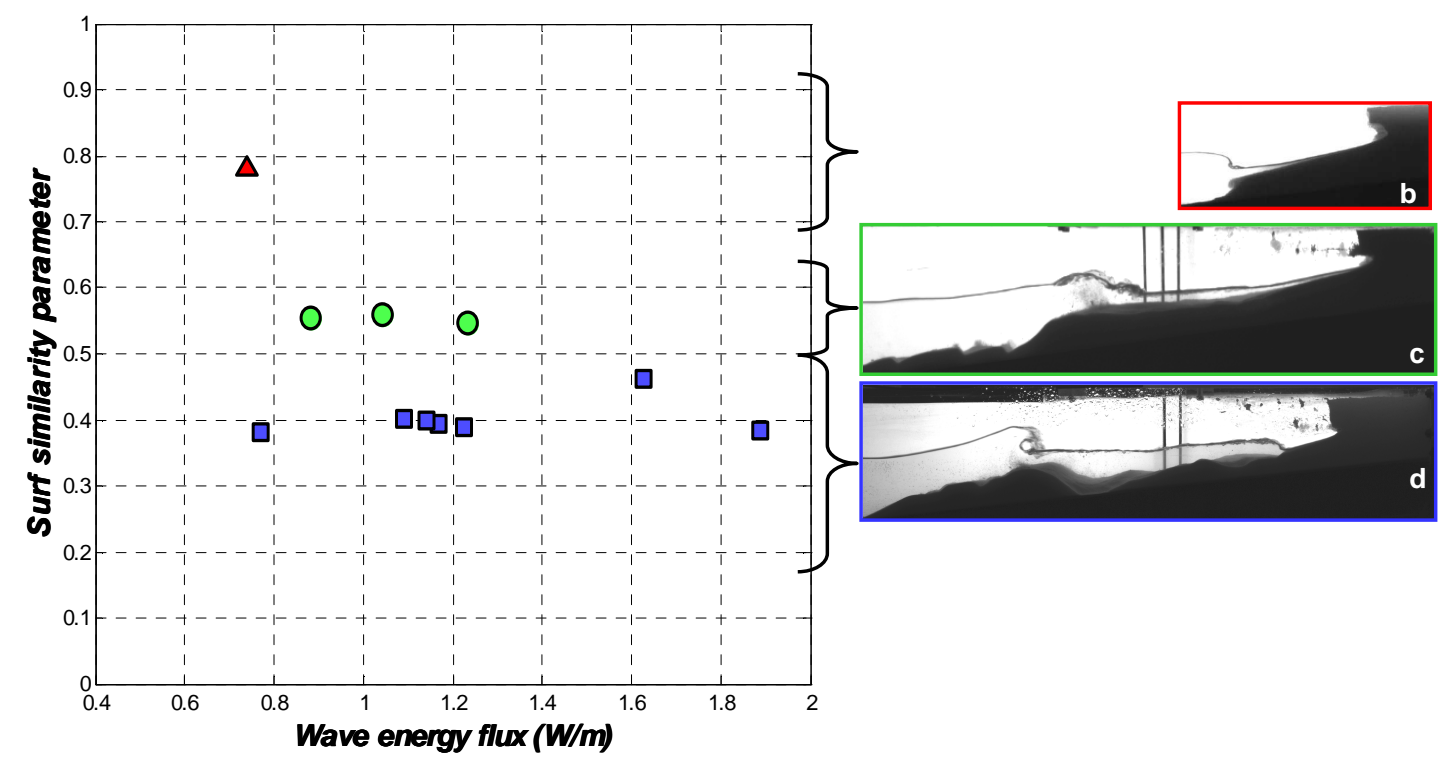

(a)

Figure 3. Tests parameters (a) in a $(F, \xi)$ plot; symbols represent the bottom profile type: bared profiles (squares), gentle or steep planar profiles (circles and triangles, respectively). Examples of side of views for each type of profiles are (b), (c) and (d), respectively.

The wave energy flux does not seem to influence the type of bottom morphology but only the characteristic length and position of the morphological features. The type of bottom morphology seems to depend mostly on the surf similarity parameter (Fig. 3): the influence of the wave shape appears to be greater than that of incident wave energy.

Most of the observed profiles reach an equilibrium (see Fig. 2 for example). However, some cases evolve towards an unsteady state: test 3 (bared profile at high energy flux) shows a self-sustained sandbar oscillation (Fig. 4-a). At the beginning of this experiment, the profile seems to reach a stable state. However, after some time (7 h $30 \mathrm{~min}$ ), sandbars begin to migrate, landward for the outer bar and seaward for the inner bar (Fig. 5). This migration lasts for about $80 \mathrm{~min}$. The return motion is faster and lasts for only $20 \mathrm{~min}$. Then, the system becomes steady for about $1 \mathrm{~h}$, before another oscillation starts. In sum, the oscillation period is about $2 \mathrm{~h} 30 \mathrm{~min}$. Outer and inner sandbar excursions are about 16 and $5 \mathrm{~cm}$, respectively.

Another case of a self-sustained oscillation of sandbar positions is observed for a higher cliff (10 $\mathrm{cm}$ ) with a lower wave energy flux (test 9). By contrast, the system dynamics is somehow different as both bar migrations occur with the same time, the oscillation frequency is higher (with a period of about $30 \mathrm{~min}$ ) and the amplitudes are approximately the same (Fig. 4-b).

Equilibrium profiles have been previously obtained in laboratory experiments (e.g., Kamalinezhad, 2004; Wang and Kraus, 2005; Grasso et al., 2009). Sandbar migrates onshore for moderate waves conditions and offshore for very energetic waves conditions (Gallagher et al., 1998; Ruessink et al., 2003). Such migrations have been observed in laboratory experiments (Grasso et al., 2009; Hoyng, 2008), and to our knowledge, sandbar oscillations have never been reported. Onshore and offshore bar migration have been observed on the field (Certain and Barusseau, 2005) for a varying wave climate. 


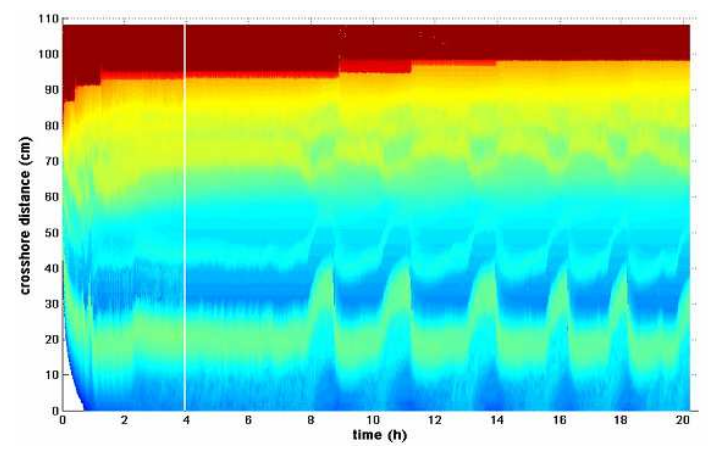

(a)

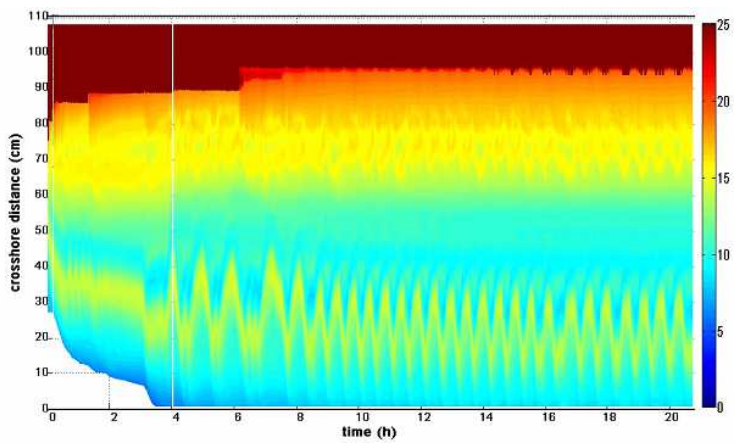

(b)

Figure 4. Same than Fig. 2 for: (a) test 3 and (b) test 9 (bared profile); color scale represents the bottom and cliff elevation (in $\mathrm{cm}$ ).

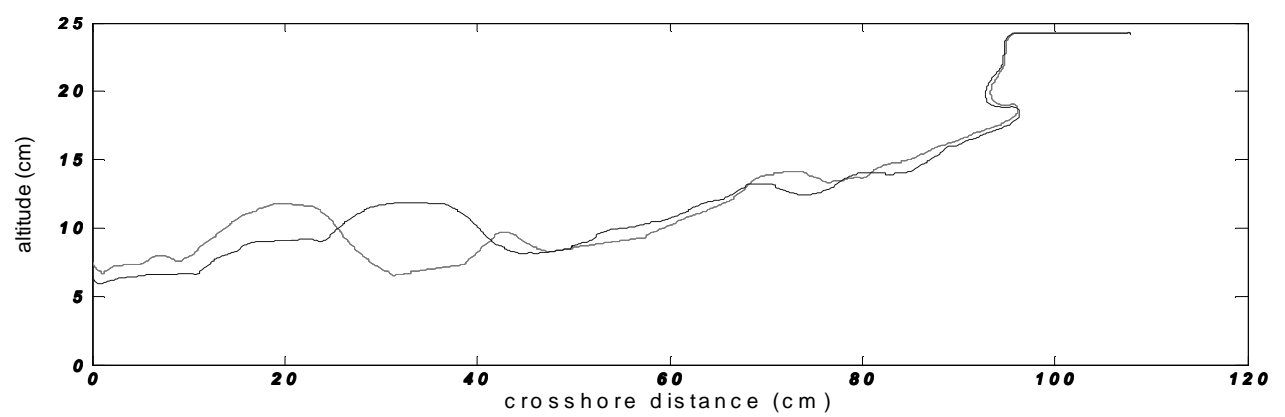

Figure 5. Bottom morphology for test 3 between each oscillation (light grey) and after the first migration (dark grey).

\section{Cliff recession rate}

We estimated the cliff recession rate as a function of the wave climate and then as a function of the sediment supply.

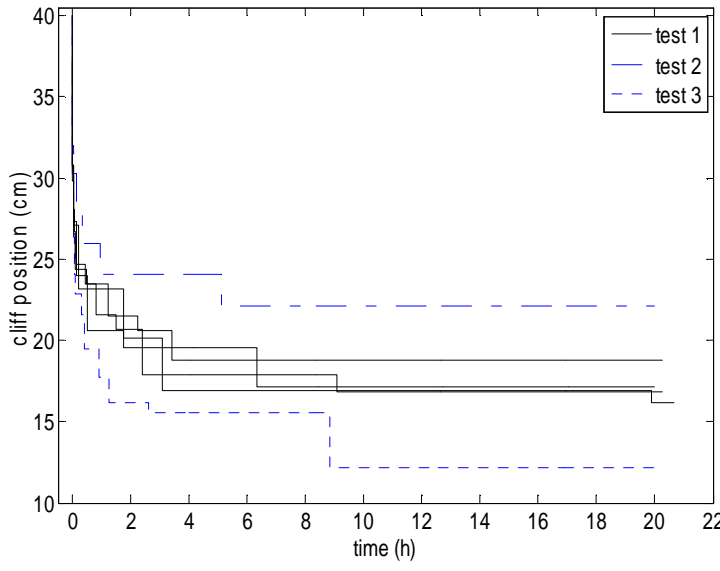

(a)

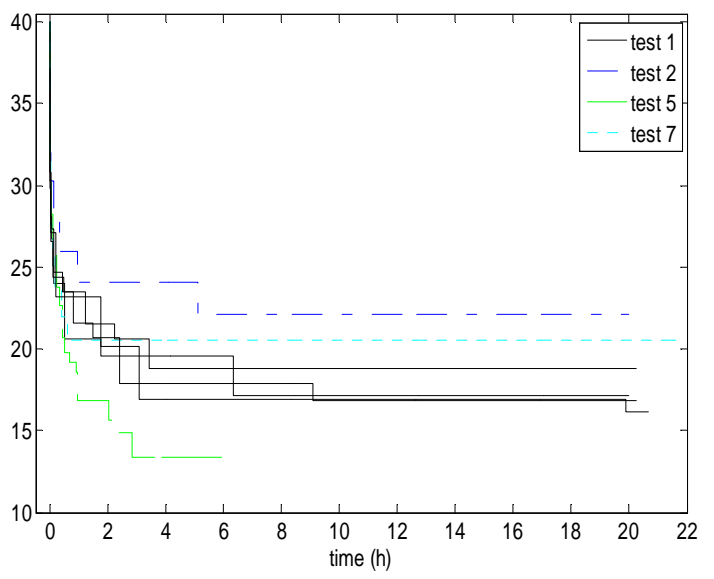

(b)

Figure 6. Time evolution of cliff position for (a) different wave energy fluxes and (b) different surf similarity parameters (i.e. different types of bottom morphology). Initial cliff position is $40 \mathrm{~cm}$.

We firstly checked that the cliff retreat is reproducible for the same parameters (tests 1-a, 1-b, 1-c, 1-d, Fig. 6). Secondly, we varied the wave energy flux and as we foresaw, the cliff recession rate increases for increasing wave energy flux (Fig. 6-a). We thus observe the same tendency as Damgaard and Dong (2004). Thirdly, for the same wave energy flux, we changed the surf similarity parameter, and 
therefore the bottom morphology. Comparing test 1 -a and test 5, one can see that cliff erosion is stronger for a gentle planar profile $(0.5<\xi<0.7)$ than for a bared profile $(\xi<0.5)$ (Fig. $6-b)$.

The influence of sediment supply in the system is studied for two perspectives: (i) periodic removal of the sandbar and (ii) variation of the cliff height. For a test with a bared profile, we removed periodically the outer sandbar during the experiment, a couple of minutes after each cliff collapse (Fig. 7). Comparing the same experiment with and without bar removal (Fig. 9-a), it appears clearly that the cliff retreat is more important with bar removal which features a quite constant recession rate, whereas it diminishes through time when the bar remains. This result is comparable with Damgaard and Dong (2004)'s results for oblique waves as they observed a constant recession rate. It allowed by the evacuation of the sediment by the longshore transport being equivalent to the bar response.

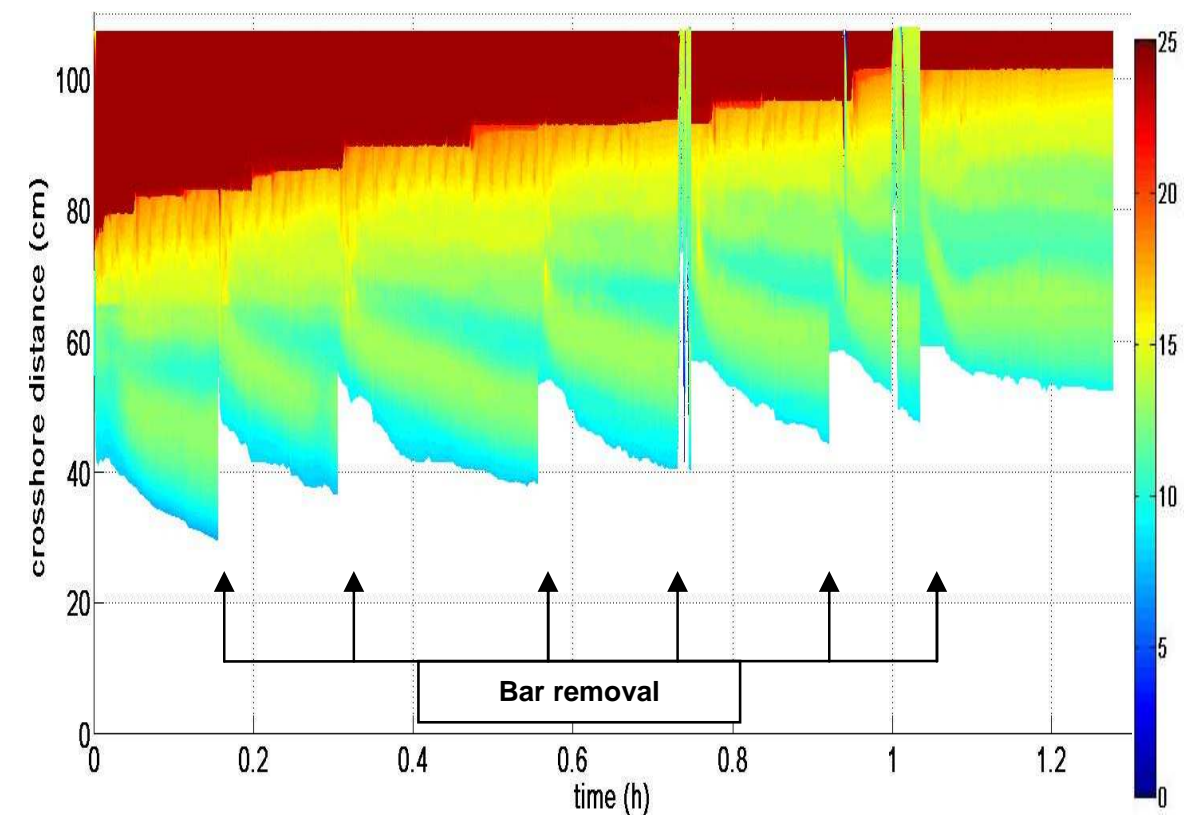

Figure 7. Same than Fig. 2, for the test 1 with sandbar removal.

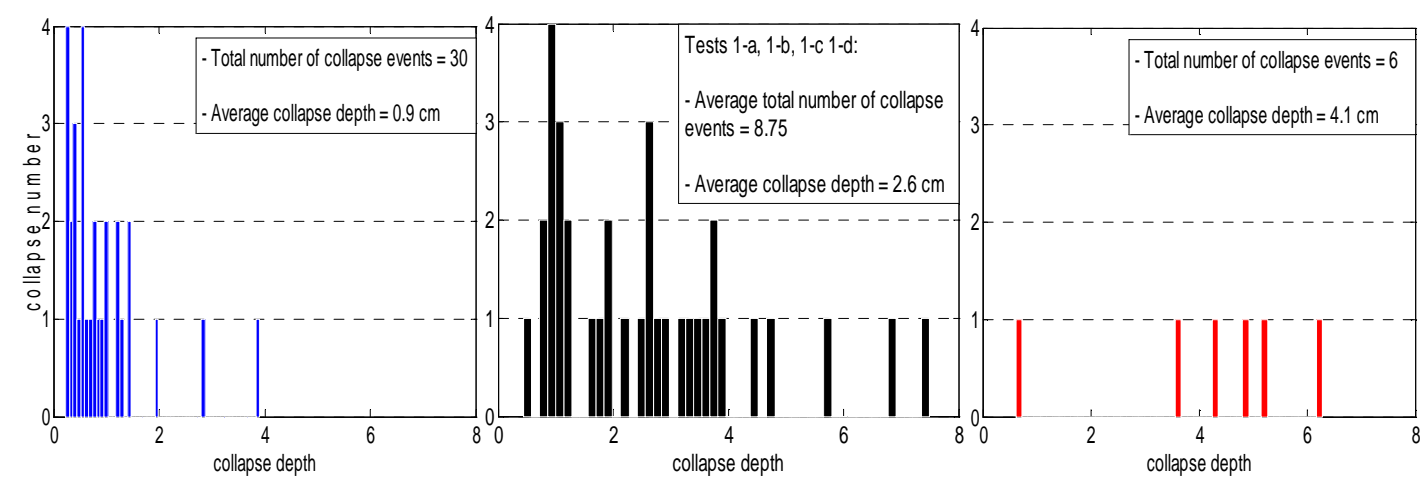

(a)

(b)

(c)

Figure 8. Histogram of collapse number in function of collapse depth for different cliff height (a) : test 10 ; $h$ $=5 \mathrm{~cm}-(\mathrm{b}):$ test $1 ; \mathrm{h}=8 \mathrm{~cm}-(\mathrm{c}):$ test $9 ; \mathrm{h}=10 \mathrm{~cm}$.

The second aspect of the results in terms of sediment supply is the influence of cliff height. For approximately the same wave climate, we performed experiments for 3 different cliff heights $(5,8$ and $10 \mathrm{~cm}$ ). We analyzed collapse events; we measured the average depth of a collapse event for the 3 cases. Fig. 8 shows that the total number of collapse events decreases with cliff height whereas average depth of a collapse event increases, and therefore average volume of a collapse event increases. The 
cliff recession rate for $\mathrm{h}=5 \mathrm{~cm}$ is greater than the one with $\mathrm{h}=8 \mathrm{~cm}$ (Fig. 9-b). Damgaard and Dong (2004)'s also noticed that cliff recession rate seems to decrease with cliff height. On the contrary, cliff recession rate for the highest cliff $(\mathrm{h}=10 \mathrm{~cm})$ is not the smallest recorded (Fig. 9-b). We thus, show cliff retreat rate as a function of cliff height is not monotonic. We note here, for $\mathrm{h}=8$ and $5 \mathrm{~cm}$, the profiles reach a stable state, whereas the $h=10 \mathrm{~cm}$ profile is characterized by a self-sustained sandbar oscillation. Cliff recession therefore depends both on cliff height and on bottom shape which depends on hydrodynamic conditions.

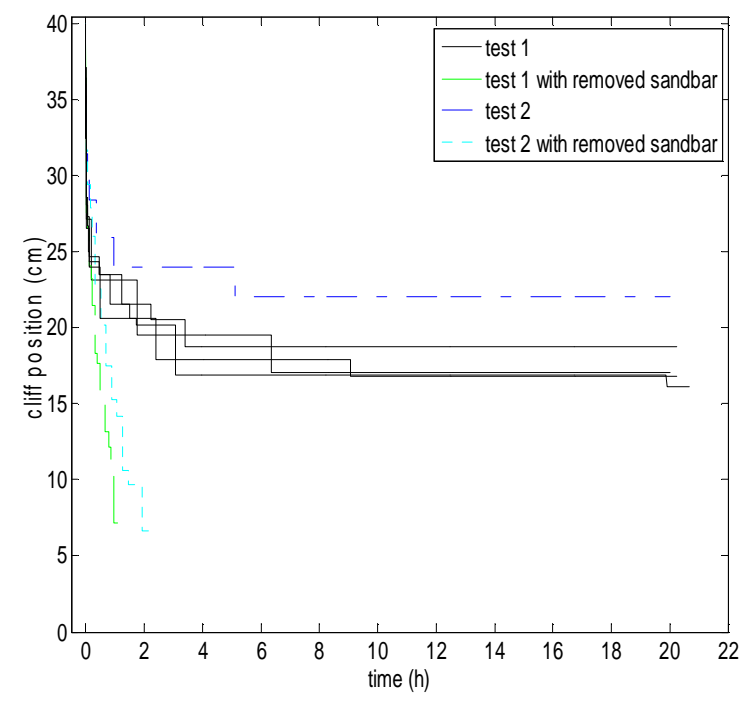

(a)

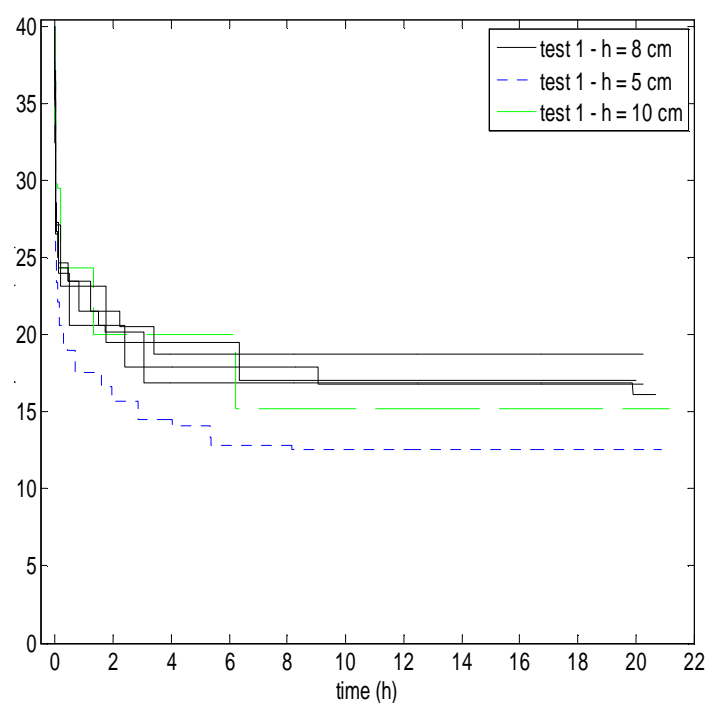

(b)

Figure 9. Evolution of cliff position (a) with bar removal and (b) for 3 different cliff heights. Cliff position is initially at $40 \mathrm{~cm}$.

\section{CONCLUSIONS}

Coastal cliff erosion by regular waves has been investigated in an experimental wave flume. Our results show that the type of bottom morphology depends strongly on the surf similarity parameter:

- $\quad \xi>0.7$ - steep planar profile.

- $0.5<\xi<0.7-$ gentle planar profile.

- $\quad \xi<0.5$ - bared profile.

For bared profiles, we either observed steady or unsteady self-sustained oscillating states for a constant wave climate. Unsteady states show self-sustained sandbars oscillations, reflecting an organization of the system governed by the hydrodynamics/morphology coupling.

The influence of cliff height on the cliff recession rate depends mostly on the self-organised material, previously mentioned; we can therefore correlate the influence of the parameters chosen with the cliff recession rate for the same bottom morphology dynamics. Thus, the cliff erosion increases with the wave energy flux and is stronger for a gentle planar profiles than for a bared profile.

We have shown that the sediment supply plays an important role on cliff recession. A periodical bar removal yields an approximately constant cliff recession rate. Our experiments show that average volume of a collapse event increases and number of collapse events decreases with cliff height.

\section{ACKNOWLEDGMENTS}

We gratefully acknowledge Institut National des Sciences de l'Univers (INSU) and PRES Université de Toulouse. PRES Université de Toulouse provided the PhD fellowship for BC.

We thank Serge Font, Grégory Dhoye, Sébastien Cazin and Hervé Ayrolles for valuable technical assistance.

\section{REFERENCES}

Certain, R. and Barusseau, J.-P. 2005. Conceptual modeling of sand bars morphodynamics for a microtidal beach (Sète, France). Bull Soc. Géol. Fr, 176(4), 343-354. 
Collins, B.D. and Sitar, N. 2008. Processes of coastal bluff erosion in weakly lithified sands, Pacifica, California, USA. Geomorphology, 97, 483-501.

Damgaard, J.S. and Dong, P. 2004. Soft cliff recession under oblique waves: physical model tests. Journal of waterway, port, coastal and ocean engineering, 234-242.

Dean, R.G. 1991. Equilibrium beach profiles: Characteristics and applications. Journal of Coastal Research, 7(1), 53-84.

Gallagher, E.L., Elgar, S. and Guza, R.T. 1998. Observations of sand bar evolution on a natural beach. Journal of Geophys. Res., 103(C2), 3203-3215.

Grasso, F., Michallet, H., Barthélemy, E. and Certain, R. 2009. Physical modeling of intermediate cross-shore beach morphology: transients and equilibrium states. Journal of Geophys. Res., 114.

Hoyng, C. 2008. Erosive and accretive coastal response. M. Sc. Thesis, WL Delft Hydraul., Deltft, Netherlands.

Kamalinezhad, M. 2004. Plages en équilibre morphologique et hydrodynamique associée. PhD Thesis, Institut National Polytechnique de Grenoble , France.

Kanyaya, J.I. and Trenhaile, A.S. 2005. Tidal wetting and drying on shore platforms: an experimental assessment. Geomorphology, 70, 129.

Larson, M. and Kraus, N.C. 1994. Temporal and spatial scales of beach profile change, Duck, North Carolina. Marine Geology, 117, 75-94.

Mansard, E.P.D. and Funke, E.R. 1980. The measurement of incident and reflected spectra using a least squares method. Proc. 17 $7^{\text {th }}$ Int. Conf. Coastal Eng., ASCE, New York, 154-172.

Nesteroff, W.D. and Mélières, F. 1967. L'érosion littorale du pays de Caux. Bull Soc. Géol. Fr, 7, 159169.

Ruessink, B.G., Walstraa, D.J.R. and Southgate, H.N. 2003. Calibration and verification of a parametric wave model on barred beaches. Coastal Engineering, 48, 139-149.

Wang, T. and Kraus, N.C. 2005. Beach profile equilibrium and patterns of wave decay and energy dissipation across the surf zone elucidated in a large-scale laboratory experiment. Journal of Coastal Research, 21(3), 522-534.

Wright, L.D. and Short, A.D. 1984. Morphodynamic variability of surf zones and beaches: A synthesis. Marine Geology, 56, 93-118. 